\section{Correlation between optic disc atrophy and aetiology: anterior ischaemic optic neuropathy vs optic neuritis}

EZ Rath1', U Rehany', S Linn² and S Rumelt ${ }^{1}$

\begin{abstract}
Background The morphologic features of swollen disc in the acute stage of optic neuritis and anterior ischaemic optic neuropathy (AION) have been extensively investigated in contrast to the morphologic features of optic disc atrophy after these events.

Objective: A prospective study to evaluate the morphologic features of optic disc atrophy 6 months or more after optic neuritis and nonarteritic AION.

compared with optic neuritis $(1: 3,8 \%)$

$(P=0.007)$. There were no significant

differences between the two groups in height of the rim, cupping, and peripapillary atrophy. Conclusions: A combination of the degree of rim pallor, location of rim pallor, and $A: V$ ratio may be of value in assessing the aetiology of optic disc atrophy when no previous clinical data are available and a compressive lesion has been ruled out. Eye (2003) 17, 1019-1024. doi:10.1038/ sj.eye. 6700691
\end{abstract}

Patients and methods A total of 35 optic discs after nonarteritic AION $(n=27)$ and 24 after optic neuritis $(n=19)$ in otherwise healthy subjects have been evaluated by direct fundoscopic examination with a +90 diopters lens and optic disc photography. The average age of patients at the onset of AION was 57.8 years (range: $38-80$ ) and at the onset of optic neuritis was 32.6 (range: 19-46). The female:male ratio was $18: 17$ in the former and $15: 9$ in the latter. The evaluated parameters included: degree of rim pallor $(0$ to +3$)$, location of rim pallor, height of rim above the retina, depth and width of cup, peripapillary retinal artery to vein $(A: V)$ ratio, and peripapillary pigment epithelial atrophy. A comparison was made also with 17 agematched normal discs of 17 patients. Statistical significance was calculated with $\chi^{2}$ and Fisher's exact test.

Results Most of the discs after AION were paler ( $+2: 70 \%,+3: 26 \%)$ than after optic neuritis (normal colour: $8 \%$, +1 : $58 \%$, $P \leqslant 0.007)$. Rim segmental involvement after AION was usually either superior 'altitudinal' (53\%) or inferior 'altitudinal' $(29 \%)$, whereas after optic neuritis, it was usually either temporal-central (papillomacular) $(42 \%)$ or diffuse temporal $(42 \%, P<0.0001)$. Discs had lower $A$ : $V$ ratio $(1: 3,40 \%)$ after $A I O N$
Keywords: optic disc; optic atrophy; diagnosis; anterior ischaemic optic neuropathy; optic neuritis

\section{Introduction}

Anterior ischaemic optic neuropathy (AION) and optic neuritis $(\mathrm{ON})$ are the two most common disorders of the optic nerve head. The appearance of the optic disc at the acute stage of AION and ON has been studied to disclose those distinguishing features that would allow clinical differentiation between the two. ${ }^{1}$ As the clinical profile of visual loss may be similar in these two entities that comprise most of the cases of neurogenic visual loss in adults, and since the clinical profiles of these entities may be overlapping $^{1,2}$ the present study was

It has been suggested that during the acute phase, altitudinal or pallid disc oedema, haemorrhages and retinal arterial attenuation are more characteristic for AION, whereas a normal-coloured optic disc without haemorrhages is more characteristic of papillitis (the anterior form of $\mathrm{ON}$ ). However, pallid disc oedema and papillary haemorrhages may performed.
${ }^{1}$ Department of Ophthalmology Western Galilee Medical Center Nahariya, Israel

${ }^{2}$ Department of Epidemiology Rambam Medical Center Haifa, Israel

Correspondence: Shimon Rumelt Department of Ophthalmology Western Galilee Nahariya Medical Center PO Box 21

22100 Nahariya, Israel

Tel: + 97249107635

Fax: + 97249107611

Received: 30 December 2002

Accepted in revised form: 10 June 2003

Presented in part at the Fourth European

Neuro-ophthalmology

Society Meeting, Jerusalem, Israel, August 1999,

International

Neuro-ophthalmology Society Meeting, Toronto, Canada, September 2000, the 104th American Academy of Ophthalmology Meeting, Dallas, TX, October 2000; and Annual Meeting of the Association for Research in Vision and Ophthalmology, Fort Lauderdale, FL, May, 2001 
appear in both papillitis, and normal appearing disc (ie minimally swollen disc without haemorrhages, changes in colour, cupping, and overlying vessels) may occur in AION. ${ }^{1,2}$

Less attention has been given to the appearance of the optic disc at the late atrophic stages of these conditions. This prospective study was undertaken to evaluate the morphologic features of optic discs at 6 months or more following well-documented nonarteritic AION or anterior $\mathrm{ON}$. We tried to correlate the findings at the acute stage as described previously and the late findings to assess the process of neuronal atrophy in these disorders.

Disc features that distinguish between previous AION and $\mathrm{ON}$ are of clinical importance, since some patients with optic atrophy have a poorly defined or inaccessible medical history. If these patients present with acute optic neuropathy in the fellow eye or with a recurrence, the proper diagnosis of the previous disorder in the contralateral eye may be beneficial for treatment and for evaluation of the prognosis.

\section{Patients and methods}

We consecutively evaluated the optic discs of 35 eyes of Caucasian patients after nonarteritic AION $(n=27)$ and 24 eyes of Caucasian patients after idiopathic anterior ON ( $n=19)$ without media opacities (such as corneal oedema or scar, cataract, or vitreous haemorrhage) 6 months or more after the acute anterior disc swelling. The initial diagnosis was made according to the combination of optic disc appearance at the acute stage and the clinical course. The criteria for the diagnosis of AION and ON were summarized elsewhere. ${ }^{3}$

The average age of patients at AION onset was 57.8 years (range: $38-80$ years) and at $\mathrm{ON}$ onset 32.6 years (range: 19-46 years) (Table 1 ). The male: female ratio was $1: 0.93$ in the former and $1: 2.8$ in the latter. Bilateral optic disc atrophy due to AION occurred in eight patients and in five due to ON. In the bilateral cases, each disc was compared with 17 arbitrarily selected eyes of 17 normal age-matched controls (age range: 23-77 years, average

Table 1 Data of patients with optic atrophy due to nonarteritic $\mathrm{AION}$ and $\mathrm{ON}$

\begin{tabular}{|c|c|c|c|}
\hline Parameter & $\begin{array}{l}\text { Anterior ischaemic } \\
\text { optic neuropathy }\end{array}$ & Optic neuritis & Controls \\
\hline No. of eyes & 35 & 24 & 17 \\
\hline No. of patients & 27 & 19 & 17 \\
\hline Gender (M:F) & $14: 13$ & $5: 14$ & $6: 11$ \\
\hline $\begin{array}{l}\text { Age in years } \\
\text { (average) }\end{array}$ & $38-80(57.8)$ & 19-46 (32.6) & 23-77 (49.8) \\
\hline
\end{tabular}

Table 2 Evaluated parameters for nonarteritic AION and ON

\begin{tabular}{|c|c|}
\hline Parameter & Judgement criteria \\
\hline Degree of rim pallor & $\begin{array}{l}\text { - } 0 \text {, no pallor (pink rim, similar } \\
\text { to the fellow normal disc or to } \\
\text { other normal discs) } \\
\text { - }+1 \text {, minimal pallor (slight pale } \\
\text { or greyish disc) } \\
\text { - }+2 \text {, moderate pallor (white } \\
\text { disc) } \\
\text { - }+3 \text {, marked pallor (chalky } \\
\text { white disc) }\end{array}$ \\
\hline Area of pallor and location & $\begin{array}{l}\text { Diffuse } \\
\text { Focal } \\
\quad \text { Segmental } \\
\text { Altitudinal }\end{array}$ \\
\hline $\begin{array}{l}\text { Rim height compared with } \\
\text { the retinal surface }\end{array}$ & $\begin{array}{l}\text { - Above } \\
\text { - At the same level } \\
\text { - Below }\end{array}$ \\
\hline Depth and width of cup & $\begin{array}{l}\text { - Shallow (normal) } \\
\text { - Moderately deep } \\
\text { - Very deep (to the level of the } \\
\text { lamina cribrosa) }\end{array}$ \\
\hline Peripapillary A:V ratio & $\begin{array}{l}\text { - } 2: 3 \text { normal } \\
\text { - } 1: 2 \text { narrow } \\
\text { - } 1: 3 \text { markedly narrow }\end{array}$ \\
\hline Peripapillary atrophy & Exist/does not exist \\
\hline
\end{tabular}

49.8 years). Of the AION group, two patients had bilateral hypertropia of +2.50 , two had bilateral myopia of less than -3.00 , one myopic anisometropia $(-8.00 \mathrm{D}$ in the affected eye and -2.00 in the fellow eye) and the rest were emmetropes. From the ON group, two had bilateral myopia of less than -3.00 and the rest were emmetropes.

Ocular medical history was obtained and complete eye examination was performed to exclude media opacities that might have interfered with the interpretation of the funduscopic findings. Patients with media opacities were excluded from the study. The pupils in both eyes were dilated before examination. The evaluated parameters included degree of rim pallor, location of rim pallor, height of rim, width of cup, peripapillary retinal artery to vein $(\mathrm{A}: \mathrm{V})$ caliber ratio, and peripapillary atrophy (Table 2).

The degree of rim pallor was divided into four categories compared with the fellow normal disc. In bilateral disease, the reference was normal disc of agematched controls without any history of ocular or system disorders. The categories were: 0 - no pallor (pink rim, similar to the fellow normal disc or to other age-matched normal discs); +1 -minimal pallor (slightly pale or greyish disc); +2 -moderate pallor (white disc); +3 - marked pallor (chalky white disc). 
The area of rim pallor was divided to either diffuse or to focal. Several patterns of focal pallor were found and grouped into segmental (pie-shaped) and altitudinal. They were further divided according to their location within the rim. The width of the cup was determined according to the cup/disc (C/D) ratio. The rim height was compared with the retinal surface and categorized as either above the retinal surface, at the level of the retinal surface, or below it. The retinal A : V ratio was calculated as the caliber ratio of the superior and inferior temporal retinal artery and retinal vein arcades adjacent to the optic disc margins.

The disc evaluation was performed in masked fashion using the same slit-lamp biomicroscope with a +90D lens. Comparison was made with the fellow normal optic disc or, in the case of bilateral disease, with normal healthy discs of comparable age-matched controls. Optic disc photographs were obtained and evaluated in masked fashion for rim pallor, area of rim pallor, height of rim, depth and width of cup, peripapillary A : V caliber ratio, and peripapillary atrophy. This evaluation was compared with the clinical observations. Statistical significance was calculated with $\chi^{2}$ test. Fisher's exact test was employed for samples with expectancy of 5 or less. $P<0.05$ was considered statistically significant.

\section{Results}

Most of the discs after AION were paler than those after $\mathrm{ON}$ (Table 3). They were paler than the uninvolved fellow discs and the age-matched normal discs (Table 4). Seventy percent of the optic discs after AION had moderate pallor (white) and $26 \%$ had severe pallor (chalky white), whereas $58 \%$ of the discs after ON had only minimal pallor (greyish), and $8 \%$ had normal pink hue (comparable with the uninvolved fellow discs and with normal age-matched discs). The differences in hue were statistically significant $\left(P \leq 0.007, \chi^{2}\right.$ test). Segmental rim pallor after AION was usually either superior 'altitudinal' (53\%) or inferior 'altitudinal' (29\%), whereas after ON it was usually either temporal-central (42\%) or diffuse temporal $(42 \%)\left(P<0.0001, \chi^{2}\right.$ test $)$. No segmental atrophy was found in the uninvolved fellow discs or in the age-matched normal controls. A diffuse pallor was noted in two fellow eyes of AION and one fellow eye of $\mathrm{ON}$, but they were only of grade +1 and may represent normal variants, since no visual field defects were

Table 3 Optic disc characteristics in nonarteritic AION and ON

\begin{tabular}{|c|c|c|c|c|c|c|c|}
\hline Parameter & & AION & ON & $\begin{array}{l}\text { Fellow } \\
\text { normal } \\
\text { eye of } \\
\text { AION }\end{array}$ & $\begin{array}{c}\text { Fellow } \\
\text { normal } \\
\text { eye of } O N\end{array}$ & $\begin{array}{l}\text { Statistical } \\
\text { significance } \\
\text { difference } \\
\text { between } \\
\text { AION } \\
\text { and ON }\end{array}$ & $\begin{array}{l}\text { Statistical } \\
\text { test }\end{array}$ \\
\hline \multirow[t]{2}{*}{ Type of atrophy } & Diffuse & $18(52 \%)$ & $12(50 \%)$ & $2(7.2 \%)$ & $1(9 \%)$ & \multirow[t]{2}{*}{$P=\mathrm{NS}$} & \multirow{2}{*}{$\chi^{2}$} \\
\hline & Segmental & $17(48 \%)$ & $12(50 \%)$ & $0(0 \%)$ & $0(0 \%)$ & & \\
\hline Area of segmental & Sup. Alt. & $9(53 \%)$ & $0(0 \%)$ & $0(0 \%)$ & $0(0 \%)$ & $P=0.003$ & Fisher exact \\
\hline \multirow[t]{3}{*}{ Atrophy } & Inf. Alt. & $5(29 \%)$ & $0(0 \%)$ & $0(0 \%)$ & $0(0 \%)$ & $P=0.05$ & Fisher exact \\
\hline & Cent. Temp. & $0(0 \%)$ & $5(42 \%)$ & $0(0 \%)$ & $0(0 \%)$ & $P<0.007$ & Fisher exact \\
\hline & Diff. Temp. & $2(12 \%)$ & $5(42 \%)$ & $0(0 \%)$ & $0(0 \%)$ & $P=\mathrm{NS}$ & Fisher exact \\
\hline \multirow[t]{4}{*}{ Degree of rim pallor } & 0 & $0(0 \%)$ & $2(8 \%)$ & $17(89.4 \%)$ & $12(85.7 \%)$ & $P=\mathrm{NS}$ & Fisher exact \\
\hline & +1 & $2(5.7 \%)$ & $14(58 \%)$ & $2(10.6 \%)$ & $2(14.3 \%)$ & $P<0.0001$ & $\chi^{2}$ \\
\hline & +2 & $24(68.6 \%)$ & $8(33 \%)$ & $0(0 \%)$ & $0(0 \%)$ & $P=0.007$ & $\chi^{2}$ \\
\hline & +3 & $9(25.7 \%)$ & $0(0 \%)$ & $0(0 \%)$ & $0(0 \%)$ & $P=0.007$ & Fisher exact \\
\hline \multirow[t]{3}{*}{$\mathrm{A}: \mathrm{V}$ ratio } & $2: 3$ & $0(0 \%)$ & $0(0 \%)$ & $7(36.8 \%)$ & $11(78.6 \%)$ & $P=\mathrm{NS}$ & Fisher exact \\
\hline & $1: 2$ & $21(60 \%)$ & $22(92 \%)$ & $8(42.2 \%)$ & $3(21.4 \%)$ & $P=0.007$ & $\chi^{2}$ \\
\hline & $1: 3$ & $14(40 \%)$ & $2(8 \%)$ & $4(21 \%)$ & $0(0 \%)$ & & \\
\hline \multirow[t]{5}{*}{ Cup/disc ratio } & 0.1 & $0(0 \%)$ & $0(0 \%)$ & $3(15.7 \%)$ & $9(64.3 \%)$ & $P=\mathrm{NS}$ & \\
\hline & 0.2 & $0(0 \%)$ & $0(0 \%)$ & $9(47.4 \%)$ & $4(28.6 \%)$ & & Fisher exact \\
\hline & 0.3 & $35(100 \%)$ & $21(88 \%)$ & $5(26.3 \%)$ & $1(7.1 \%)$ & & \\
\hline & 0.4 & $0(0 \%)$ & $3(12 \%)$ & $1(5.3 \%)$ & $0(0 \%)$ & & \\
\hline & 0.5 & $0(0 \%)$ & $0(0 \%)$ & $1(5.3 \%)$ & $0(0 \%)$ & & \\
\hline \multirow[t]{2}{*}{ Rim height } & Above retina & $4(11 \%)$ & $2(8 \%)$ & $1(5.3 \%)$ & $1(7.1 \%)$ & $P=\mathrm{NS}$ & $\chi^{2}$ \\
\hline & Same level & $31(89 \%)$ & $22(92 \%)$ & $18(94.7 \%)$ & $13(92.9 \%)$ & & \\
\hline Peripapillary atrophy & & $1(3 \%)$ & $3(12 \%)$ & $1(5.3 \%)$ & $1(7.1 \%)$ & $P=\mathrm{NS}$ & Fisher exact \\
\hline
\end{tabular}

AION - anterior ischaemic optic neuropathy, ON - optic neuritis, 0 - pink rim (comparable to the fellow normal eye and standardized normal eyes), +1 - minimal pallor (greyish), +2 - moderate pallor (white), +3 - severe pallor (chalky white), A: V ratio - retinal arterial:venous ratio, NS - nonsignificant, cent. - center, diff._- diffuse, alt. - altitudinal, temp. - temporal, sup. — superior, inf. - inferior. 
Table 4 Optic disc characteristics of age-matched normal controls

\begin{tabular}{llc}
\hline Parameter & \multicolumn{2}{l}{ Age-matched normal controls $(n=17)$} \\
\hline Type of atrophy & Diffuse & $2(11.8 \%)$ \\
& Segmental & $0(0 \%)$ \\
Area of segmental atrophy & Sup. alt. & $0(0 \%)$ \\
& Inf. alt. & $0(0 \%)$ \\
& Cent. temp. & $0(0 \%)$ \\
& Diff. temp. & $0(0 \%)$ \\
Degree of rim pallor & 0 & $15(88.2 \%)$ \\
& +1 & $2(11.8 \%)$ \\
& +2 & $0(0 \%)$ \\
A:V ratio & +3 & $0(0 \%)$ \\
& $2: 3$ & $10(58.9 \%)$ \\
C/D ratio & $1: 2$ & $6(35.3 \%)$ \\
& $1: 3$ & $1(5.9 \%)$ \\
& 0.1 & $2(11.8 \%)$ \\
Rim height & 0.2 & $7(41.2 \%)$ \\
Peripapillary atrophy & 0.3 & $4(23.5 \%)$ \\
& 0.4 & $4(23.5 \%)$ \\
\hline
\end{tabular}

cent.-centre, diff.-diffuse, alt.-altitudinal, temp.-temporal, sup.- superior, inf.-inferior.

encountered in these eyes. Discs had lower $\mathrm{A}: \mathrm{V}$ ratio $(1: 3,40 \%)$ after AION compared with ON (1:3, $8 \%$ eyes) $\left(P=0.007, \chi^{2}\right.$ test). However, $63.2 \%$ of the fellow AION discs had also lower $\mathrm{A}: \mathrm{V}$ ratio compared with agematched normal discs. There were no significant differences between the AION and ON discs in rim height, disc cupping, and peripapillary atrophy.

However, it should be noted that discs with optic atrophy due to AION and ON had usually larger cups compared with their uninvolved fellow discs $(P<0.0001$, Fisher's exact test). The $\mathrm{C} / \mathrm{D}$ ratio differences ranged between $0.1-0.2$.

\section{Discussion}

Our data indicate statistically significant differences in the morphology of optic disc atrophy after nonarteritic AION as compared with after ON in three parameters: the area of involvement, the degree of pallor, and the $\mathrm{A}: \mathrm{V}$ ratio. When the optic atrophy is segmental (sectorial), an altitudinal pattern is characteristic for AION, whereas temporal pallor (diffuse temporal or papillomacular) is characteristic for ON. Optic discs are paler and the retinal arteries are thinner after AION compared with those after ON. These data allow estimation of the cause of optic nerve atrophy due to AION and ON with relative confidence based on clinical observation of the optic disc.

Previous data demonstrated that during the acute stage more discs were diffusely swollen in ON patients than with AION (89 vs 61\%, respectively). ${ }^{1}$ When disc oedema was segmental at the acute stage, it was altitudinal three times more commonly in AION than in ON (39 vs 11\%). If we consider late disc atrophy as consecutive morphologic equivalent of acute disc oedema, we may extrapolate regarding the course of these features. Our data are qualitatively, but not quantitatively, similar to that of the previous report of acute stage observations. ${ }^{1}$ We found fewer optic discs with diffuse atrophy (AION:ON, 50:50\%) compared with the report of the acute disc oedema. We found altitudinal pallor more common in the AION group than altitudinal oedema at the acute stage in the previous study, and none at the late stage of ON group. It is postulated that oedematous areas eventually become atrophied, while adjacent intact areas may remain intact in some cases despite the possible pressure created by the adjacent swollen tissue. Confirmation of this hypothesis may be performed in future studies by monitoring and documenting the development of optic disc atrophy following the acute stage of AION and ON comparing the relationship between swelling and pallor areas.

According to Warner $e t a l,{ }^{1}$ during the acute stage, acute disc pallor, and retinal arterial attenuation were more common in AION than in papillitis (35 vs 3\%, and 33 vs $5 \%$, respectively). Although our findings at the late stage are qualitatively similar, in our study more AION patients had optic disc pallor and arterial attenuation, suggesting that more AION patients acquire ischaemic damage during disc oedema resolution.

Warner et $a l^{1}$ found that patients with acute papillitis have a tendency for diffuse disc involvement, and this may be reflected by the morphology of the disc after the resolution of the acute stage. In acute papillitis, the discs are usually hyperaemic or normal in colour, suggesting that more vessels and probably axons per certain area are intact due to different damage. This is followed by less disc pallor at the atrophic stage as found in our study and may be one explanation for better visual prognosis in these patients compared with AION.

We observed a higher C/D ratio of 0.1-0.2 in the AION and the ON discs compared with the uninvolved fellow discs and the normal age-matched discs $(P<0.0001)$. The increased C/D ratio was minimal and may represent an observer error. Otherwise, it may be explained by optic nerve axonal death. Pathologic cupping was not detected and all the discs had a C/D ratio of less than 0.4 reflecting the average $C / D$ ratio of the fellow normal eyes in our study and in the normal population. ${ }^{4}$ In a previous report, cupping of the optic disc was documented in 10\% of the nonarteritic AION and in 50\% of the eyes with arteritic AION. ${ }^{5}$ It was also noted by other anecdotal reports. ${ }^{6-9}$ However, some of these eyes had high intraocular pressures or large physiologic cups 
in the fellow eyes. Others found that C/D ratio in optic atrophy due to $\mathrm{AION}, \mathrm{ON}$, and optic compression was similar to the fellow eyes. ${ }^{10}$

Although the involved atrophied rim was thinner and whiter than the uninvolved rim in the same eye, thinning was not as deep as the depth of the cup allowing detection of the contour by observation. Our C/D ratio findings were similar to Radius and Maumenee findings, ${ }^{10}$ which showed that most of the $C / D$ ratios were 0.4 or less.

We have not found a significant statistical difference between the C/D ratio of $\mathrm{AION}$ and ON. Moreover, the discs following AION did not show small cupping as may be expected from crowded discs or 'discs at risk' for developing AION. ${ }^{11}$ However, we did not evaluate the relationship between the $\mathrm{C} / \mathrm{D}$ ratio and the total disc area, which might be a better parameter for disc crowding. Differences in the appearance of the optic discs could not be explained by different refractive errors since the refractive errors were similar between the involved and the fellow eyes.

We did not observe significant peripapillary atrophy in either AION and ON groups, nor did others. ${ }^{12}$ Peripapillary atrophy, however, was reported in advanced chronic glaucoma. ${ }^{13}$ It is possible that this difference between optic atrophy due to AION and ON compared with glaucoma resides in different pathogenetic mechanisms of these entities. The intraocular pressure in glaucoma is out of proportion for the resistance of the optic disc tissues and may result in compression of the rim on the adjacent short posterior ciliary branches which may collapse eliminating the blood supply to the peripapillary tissues resulting in peripapillary atrophy.

The knowledge of characteristic atrophy patterns is invaluable when medical history of patients with optic atrophy is unavailable, especially with recent onset of swelling of the fellow eye optic disc (pseudo FosterKennedy). The cause of optic atrophy in these patients may be essential for proper management and evaluation of the visual prognosis.

Limited data are available regarding the relationship between the morphologic features of optic disc atrophy and its aetiologies. Jonas et $a l^{14}$ showed that optic discs with atrophy had narrower parapapillary retinal vessels and area of pallor larger than the cupping area compared with normal optic discs. However, they did not correlate between the cause for the atrophy and the optic disc morphology. Trobe et $a l^{15}$ have found that discs after AION tended to have diffuse pallor, whereas discs after $\mathrm{ON}$ had typical segmental temporal pallor. In their study, optic discs after AION did not differ by altitudinal atrophy from discs after $\mathrm{ON}$, in contrast to our study.
Observation on the optic discs may be used as an alternative or in conjunction with employment of visualevoked potentials. Visual-evoked potentials may be used to differentiate between AION where the amplitude is decreased and $\mathrm{ON}$ where the latency is increased. ${ }^{16}$ Optic disc observation is simpler and may be especially advantageous since visual-evoked potentials may return to normal in follow-ups of $35 \%$ of the patients with $\mathrm{ON} .^{17}$

We suggest that the pattern of segmental disc pallor, the degree of pallor, and the retinal peripapillary $\mathrm{A}: \mathrm{V}$ ratio may be used as reliable parameters to distinguish between $\mathrm{AION}$ and $\mathrm{ON}$ at the atrophic stage. They may be combined with other available clinical history such as the age at the onset and ocular pain. Optic discs with markedly $(+3,+4)$ segmental altitudinal pallor and narrow $\mathrm{A}: \mathrm{V}$ ratio suggest previous AION. Optic discs with either normal colour or mild pallor $(+1)$ that is segmental temporal or nasal, and near normal $\mathrm{A}: \mathrm{V}$ ratio suggest previous $\mathrm{ON}$.

\section{Acknowledgements}

We appreciate the assistance of Boris Futerman, BSc, in the statistical analysis.

\section{References}

1 Warner JEA, Lessell S, Rizzo JF, Newman NJ. Does optic disc appearance distinguish ischemic optic neuropathy from optic neuritis? Arch Ophthalmol 1997; 115: 1408-1410.

2 Rizzo JF, Lessell S. Optic neuritis and ischemic optic neuropathy: overlapping clinical profiles. Arch Ophthalmol 1991; 109: 1668-1672.

3 Lee AG, Brazis PW. Clinical Pathways in Neuro-ophthalmology. An Evidence- based Approach. Thieme: New York, 1998; pp 25, $49,50$.

4 Armaly MF, Sayegh RE. The cup-disc ratio. The findings of tonometry and tonography. Arch Ophthalmol 1969; 82: 191-196.

5 Quigley H, Anderson DR. Cupping of the optic disc in ischemic optic neuropathy. Trans Am Acad Ophthalmol Otolaryngol 1977; 83: 775-762.

6 Miller S. The enigma of glaucoma simplex. Trans Ophthalmol Soc UK 1972; 92: 563-584.

7 Hayreh SS. Pathogenesis of cupping of the optic disc. $\mathrm{Br} \mathrm{J}$ Ophthalmol 1974; 58: 863-876.

8 Eagling EM, Saunders MD, Miller SJH. Ischemic papillopathy: clinical and fluorescein angiographic review of 40 cases. Br J Ophthalmol 1974; 58: 990-1008.

9 Trobe JD, Glaser JS, Cassady J, Herschler J, Anderson DR. Nonglaucomatous excavation of the optic disc. Arch Ophthalmol 1980; 98: 1046-1050.

10 Radius RL, Maumenee AE. Optic atrophy and glaucomatous cupping. Am J Ophthalmol 1978; 85 145-153.

11 Doro S, Lessel S. Cup-disc ratio and ischemic optic neuropathy. Arch Ophthalmol 1985; 103: 1143-1144. 
12 Jonas JB, Xu L. Optic disc morphology in eyes after nonarteritic anterior ischemic optic neuropathy. Invest Ophthalmol Vis Sci 1993; 34: 2260-2265.

13 Tuulonen A, Jonas JB, Valimaki S et al. Interobserver variation in the measurements of peripapillary atrophy in glaucoma. Ophthalmology 1996; 103: 535-541.

14 Jonas JB, Nguyen NX, Naumann GOH. Optic disc morphometry in simple optic nerve atrophy. ACTA Ophthalmol 1989; 67: 199-203.
15 Trobe JD, Glaser JS, Cassady JC. Optic atrophy. Differential diagnosis by fundus observation alone. Arch Ophthalmol 1980; 98: 1040-1045.

16 Cox TA, Thompson HS, Hayreh SS, Snyder JE. Visual evoked potential and pupillary signs. A comparison in optic nerve disease. Arch Ophthalmol 1982; 100: 1603-1607.

17 Heinrichs IH, McLean DR. Evolution of visual evoked potential in optic neuritis. Can J Neurol Sci 1988; 15: 394-396. 